\title{
Perceived Agenda-Setting Effects: Factors Impacting Awareness of Media Influence
}

\begin{abstract}
SU Lin-sen
Beijing Jiaotong University, Beijing, China

Using the air pollution in Beijing as the example, the current study examines respondents' perceived media's impact on both issue agenda-setting (first-level) and attribute agenda-setting (second-level) effects through a self-reported telephone survey in January 2015. The results confirm media's impact on the awareness of issue agenda-setting effects but only partly support attribute agenda-setting effects. The results show perceived media credibility, direct personal experience, interpersonal communication, and media exposure all positively influence the perceived issue agenda-setting effects by individuals. Whereas media credibility and direct personal experience influence perceived attribute agenda setting effects. The findings suggest that Chinese media are effective in telling people what to think about, but not effective in telling people how to think.
\end{abstract}

Keywords: issue agenda-setting, attribute agenda-setting, air pollution, media exposure

\section{Introduction}

The agenda-setting process of the news media has been supported in hundreds of studies. The news media highlight certain issues, transmitting salience cues regarding their relative importance. The public learns about the important issues of the day from this coverage. This process has been called "inadvertent" (McCombs, 1997) since the media coverage usually is constructed from real world events and ostensibly not the outcome of some overt bias or manipulation. Public concern with issues in the media thus is a natural outcome based on social learning. Three questions about this process are addressed in the current study. First, does this agenda-setting process function similarly when government exerts a great deal of influence over media coverage? In the case here, does agenda setting occur in China, a country where the Chinese government controls the media? Second, do members of the public perceive this media influence on their attitudes toward individual issues? In the current study, do survey respondents believe media coverage of air pollution has had an influence on their attitudes toward this issue? Finally, do attitudes toward the news media influence the perceived strength of agenda-setting awareness? Do respondents who believe that the news media are credible perceive stronger agenda-setting effects than respondents who do not trust the media?

The current study will examine agenda setting in China through public perceptions regarding air pollution. Air pollution is an immensely important issue for both citizens and the government. It contributes to an estimated 1.6 million deaths a year in China (Levin, 2015). Beijing, the Chinese capital and center of politics and culture, has for many years suffered from serious air pollution. It provides an ideal event for agenda-setting research, for environmental issue has been consistently among the top concerns of both media and the public,

SU Lin-sen, Associate Professor, Ph.D., Department of Communicartions, Beijing Jiaotong University. 
and audiences also depend heavily upon media on the environment (e.g., Atwater, Salwen, \& Anderson, 1985).

Our study, in addition to being conducted in a country with a strict governmental control, differs from traditional agenda-setting research in another important ways. The current study attempts to examine a concept that is different yet related to salience: self-awareness of the agenda-setting effect. The vast majority of studies have found strong supports for the transfer of salience from media to public. Are members of the public aware of this media influence? Rather than relying on an open-ended question about the most important problem facing China, our survey asked respondents to estimate the influence news coverage has had on their views of the issue of pollution. Are respondents aware of this "inadvertent" effect? Thus, the dependent variable here is perceived media impact on individual views of air pollution. The final data come from a telephone survey of 697 respondents in Beijing.

Examining the perceptions of media influence provides an extension to agenda-setting research. If respondents believe the media exerted a powerful influence on their views, this would suggest additional support for an active processing model of agenda setting (Wanta, 1997). In other words, high exposure to the media and positive views regarding the credibility of the news associated with perceptions of a strong agenda-setting effect would demonstrate that respondents may think the media have a strong impact on them yet continue to use the media as information sources and view the media positively.

\section{Literature Review}

\section{Perceived Agenda-Setting Awareness}

The key concept and the dependent variable of the current study are perceived agenda-setting effect, which is different from traditional agenda setting effects in the several aspects. Theoretically, the traditional agenda-setting effect of comparing the issue or attribute salience between media agenda and public agenda suffers from potential existence of reversed impact from the public to media. It assumed the impact from media to the public, but correlation between the two cannot guarantee the causality. To a large extent, the media would like to cater to the audience to expand their presence.

The conventional measurement of survey-content comparison bases on aggregate data, and the unit of analysis is issue. Therefore it ignored the impact of individual characteristics on the agenda setting process, which some individuals are more susceptible to than others (Wanta, 1997). As it is based on aggregate data of issue, it decreased the statistical power because of limited cases. The survey-based research employed here is relatively simpler compared with survey-content comparison and it is also simpler than some other measurement at individual level, such as agenda-setting susceptibility (Wanta, 1997).

\section{Agenda-Setting in China}

China has seldom had empirical agenda-setting examinations, though agenda-setting theory was introduced into China in the 1980s (ZHANG, SHAO, \& Bowman, 2012), soon after the reform and opening-up policy. Since the early 1990 s, it has been accepted with a great deal of enthusiasm, mainly because this theory fits the communist perception of the role of the media and its emphasis on the media's influence in guiding public opinion, which is linked to effective propaganda and public opinion steering (HE, 2009). At the very beginning of its introduction to China, many Chinese scholars did much work translating agenda-setting studies, mainly the early studies of Maxwell McCombs. The agenda-setting studies witnessed a great increase from the 1990s on and the number of Chinese agenda-setting studies increased from 1994 with only one article to 206 articles in 2008 (LUO, 2013). 
But many Chinese scholars confused agenda-setting with agenda-building and they mainly interpreted agendas from the media perspective, but rarely correlated the media's agenda with the audience's agenda. The only existing national empirical agenda-setting examination in China was conducted in 2000 (ZHANG et al., 2012), by comparing the media content analysis and public polls.

The relatively low socioeconomic status of Chinese may have direct and indirect impacts on the agenda-effects in China. The collectivism-oriented culture calls for individual sacrifice to the nation, which results in the divergence of personal agendas and the national agenda, that is, what is the most important for the country is not the most important to individuals (Zhang et al., 2012). Therefore, in an authoritarian country such as China, the agenda-setting effects are assumed to be low because of the lack of relevance of media among the public, also because agenda-setting effects occur "wherever there is a reasonably free and open media and political system" (McCombs, 2013, pp. 79-80). There is still a need for more research on agenda setting in China with the limited marketization and rapid diffusion of Internet recently. From the perspective of impacts on agenda-setting, the following factors should be considered.

\section{Media Credibility}

Media credibility (or trust) is a widely examined psychological variable, which plays some roles in agenda-setting effects (e.g., Wanta \& HU, 1994), and media credibility's positive role in agenda setting has been generally confirmed. Logically, if a message is transmitted by a highly credible medium, individuals would be more likely to expose themselves to the medium and believe what the medium says, resulting in high agenda-setting effects. ZHU (1997) argued that media credibility played a greater role in China, given the unique structure and functionality of the Chinese media system, and he found unambiguous and consistent evidence that media credibility is the single most significant and strongest predictor of audiences' attitudes and behaviors, among a host of demographic, socioeconomic, and media exposure variables. It has been found that the Chinese media have more freedom to report the less sensitive issues like environmental pollution and media coverage on environmental pollution is more open and transparent (DUAN \& Takahashi, 2016). Individuals who trust the media would tend to believe what media report on environmental pollution, resulting in stronger agenda-setting effects. As the media in China tend to focus on positive or constructive coverage, individuals would tend to think positively of the reality covered by media. Besides the direct impact on the agenda-setting effect, media credibility has an indirect impact on exposure (Johnson \& Kaye, 2000), especially on those relatively transparent coverage on environments, which would influence the media effect. Therefore, the following hypotheses are put forward:

(1) H1a: Individuals who believe the media are credible perceive a stronger influence by the media compared with those who do not believe the media are credible;

(2) H1b: Individuals who believe the media are credible think positively about issues covered by media compared with those who do not believe the media are credible.

\section{Personal Experience}

Logically, if individuals have little personal experience with an issue, the media would be the main source for information about the issue. Some previous studies showed that the less direct experience individuals have with issues, the more likely they would use the media to get the information, then the more likely the agenda-setting effect happens (e.g., Dearing \& Rogers, 1996; Lasorsa \& Wanta, 1990; ZHU, Watt, Snyder, YAN, \& JIANG, 1993; Zucker, 1978). Previous studies found that media influence was smaller for obtrusive 
issues compared with unobtrusive issues (Zucker, 1978) and obtrusiveness was usually operationalized at individual level as the perceived amount of personal experience a person has with the issue (Demers, Craff, Choi, \& Pessin, 1989). On the other hand, direct personal experience with an issue can also sensitize an individual to an issue and further information is sought from the media. Therefore, personal experience may enhance the media's agenda-setting effect on the issue (Iyengar \& Kinder, 2010; Lasorsa \& Wanta, 1990). We prefer to believe the positive influence based on personal experience with air pollution. The heavy smog in Beijing, which residents directly experience, may motivate them to learn more about the possible hazard. The more exposure to air pollution, the more they would seek additional information on the issue from media and other sources. Therefore, they would perceive stronger influence by media on the issue, and thus they would be more susceptible to agenda-setting effects. As the people who live in the environment with air pollution outside would lead to their negative impression on it, we assume that personal experience will lead to negative impact from media. Based on the literature, we put forward the following hypotheses:

(1) H2a: The more personal experience that individuals have with air pollution, the more likely they perceive media influence on the issue;

(2) H2b: The more personal experience that individuals have with air pollution, the more negatively they think of media's impacts about the issue.

\section{Media Exposure}

Media exposure is a factor in agenda-setting because the public's access to media is a prerequisite for the agenda-setting effect (Miller \& Wanta, 1996). In general, media effects research posits a significant relationship between the audience exposure to the media and the magnitude of the effects, with various conditions as intervening factors in the relationship (Lee, 2015). Significant positive impact was confirmed by most of the past studies (Gross \& Aday, 2003; Lasorsa \& Wanta, 1990; Miller \& Wanta, 1996; Mullins, 1977; Wanta, 1997), though some studies did not find an influence (Weaver, ZHU, \& Willnat, 1992), or its role in agenda-setting was unclear (Lee, 2015). We proposed the exposure to media positively predicts agenda-setting effects in restrictive and limited information channels. Meanwhile, the media under strict regulation of the government in China stresses the constructive role of media in national progress and social stability would positively impact the audience. The dominance of positive reports is a long tradition for Chinese media. DUAN and Takahashi (2016) shows that contrary to US media, Chinese (state) media cover environmental issue positively, which is in accordance with the fundamental ideology of communism, nationalism, and developmentalism. Meanwhile, the convenience of media use logically influences the media exposure and finally influences agenda-setting effects. Therefore, we posit the following hypotheses:

(1) H3a: The more that individuals use the media, the more salient an issue is to the individuals;

(2) H3b: The more that individuals use the media, the more positively they think of media's impacts about the issue;

(3) H3c: Individuals who cannot access media conveniently are less likely to perceive agenda setting effects;

(4) H3d: Individuals who cannot access media conveniently are less likely to think positively about media's impacts on the issue.

\section{Interpersonal Communication}

The role of interpersonal communication in the agenda-setting process has been investigated even from the beginning of agenda-setting research (McCombs \& Shaw, 1972; McLeod, Becker, \& Byrnes, 1974; Shaw, 
1977); however, the studies on this aspect provided mixed results. Previous studies found interpersonal communication increased agenda-setting effects (Atwood, 1980; McLeod et al., 1974; Shaw, McCombs, Weaver, \& Hamm, 1999), inhibited the agenda-setting effects (Atwater et al., 1985; Mendelsohn, 1996), or had no effects at all (Lasorsa \& Wanta, 1990). The two-flow step flow of communication, well established before agenda-setting, claimed opinion leaders would mediate the interaction between media agenda and public agenda. Therefore, interpersonal communication plays a role in agenda-setting process, which can be viewed as agenda diffusion, an integrated process of interpersonal communication and media effects (Vu \& Gehrau, 2010). Some studies explained the relatively mixed results on interpersonal impact. Wanta and WU (1992) found that interpersonal communication enhanced agenda-setting effects when the discussions dealt with issues covered in the media. However, when the discussions dealt with issues that received little coverage in the media, interpersonal communication competed with the media in agenda setting. McLeod et al. (1974) proposed that the differences may be due to the fact that personal-level (intrapersonal) agendas were sometimes quite different from social-level (perceived community) agendas. Interpersonal communication may inhibit the agenda-setting effects when these agendas differ and would enhance agenda-setting when they are similar (Weaver et al., 1992). As a highly covered social issue with similar attention from the media and public, we have enough justification to believe interpersonal communication will enhance the agenda-setting effects. What is more, the fast diffusion of social media in China, e.g., Weibo, Wechat, increases the interaction among people both online and offline. Interpersonal communication, including social media discourse, has often been full of negative news on air pollution that is prohibited from traditional media, partially owing to the relatively loose censorship. Different from official/mainstream media exposure, exposure to social media discourse on air pollution gives people a different perspective. King, PAN, and Roberts (2013) found that the governments' censorship focuses more on avoiding collective controversial action than "defend the government, its leaders, and their policies from criticism". Therefore, we propose the following hypotheses:

(1) H4a: The more interpersonal communication individuals take part in, the more likely that they perceive media influence;

(2) H4b: The more interpersonal communication individuals take part in, the more negatively they think about the media's impacts on the issues.

\section{Control Variables}

Because demographic variables influence how individuals use and process information in the news media, these factors could ultimately have a great deal of influence on the agenda-setting process (Wanta, 1997, p. 20). Thus, age (e.g., Coleman \& McCombs, 2007), education (e.g., Weaver, 1981), gender, and income (e.g., Hill, 1985) all may directly influence media exposure and information comprehension, resulting in an impact on agenda-setting effects. In this study, we treat demographics as control variables.

\section{Research Methods}

The data collection here is different from the classic method of comparison between a public opinion survey and a news media content analysis. We collected data through a self-reported telephone survey, which was similar to survey-based agenda-setting studies employed previously (e.g., Gross \& Aday, 2003; Weaver et al., 1992).

There are more and more media outlets that can influence the audience regarding what to think about and how to think, especially for those omnipresent social media, such as Weibo (microblog, similar to Twitter), 
RenRen (similar to Facebook), Wechat, and other never-ending changes and improvement of new platforms. According to the 37th Internet Development Report of China by the China Internet Network Information Center (CNNIC) (CNNIC, 2016), the number of Internet users in China reached 688 million by the end of December 2015, with a penetration rate of Internet of 50.3\%, and among them, mobile Internet users stood at 90.1\%. In such circumstances full of information sources and complicated by the interaction between mass media, social media, and interpersonal communication, we cannot analyze all media contents that may influence individuals. So it is hard to employ the classic method based on the comparison of survey and content analysis. Therefore we examine the awareness of agenda-setting effects based on a self-reported questionnaire survey.

The dependent variable for first level agenda setting - perceived media effects on issue salience - was measured by the question: "How strongly is your concern on air pollution (issue) affected by the coverage of media (such as newspapers, magazines, radio, TV, the Internet and mobile phones) on this issue?". Response categories were: extremely affected, affected, not sure, somewhat affected, not affected at all, and not concerned about the issue of air pollution.

The dependent variables for second level agenda setting — perceived media effects on affective attributes, or positive, neutral, or negative attitudes toward air pollution —was measured by the question: "Which one of your following attitudes was reinforced by the coverage on air pollution of media (such as newspapers, magazines, radio, TV, the Internet and mobile phones)?". Response categories were: the problem of air pollution aroused the concern on the issue of circumstances, which is helpful to upgrade the modes of production and life (positive), the air pollution is very harmful (negative), uncertain, or neutral, and no impact by media coverage on air pollution (effectless). Thus, a positive view of air pollution would imply hope for the future, while a negative view of air pollution would imply a lack of hope.

Media credibility was defined as the dummy variable of whether the respondents trust media or not, and it was measured by the question: "Which medium do you trust most?". Response categories were: newspapers, magazines, radio, TV, Internet, and none. Those trusting newspapers, magazines, radio, TV, or Internet have credibility on media, and those answering none have no credibility on media.

Personal experience was measured by the question: "To what extent do you have personal experience of air pollution?". Response categories included very much, much, not sure, little, and very little.

Media exposure was measured by a 7-point scale of "how many days did you use the following media in the last week" on newspaper, magazine, TV, radio, and Internet (PC Internet and Mobile Internet). And the media exposure is the mean of them.

Interpersonal communication is measured with the question: "Are you interested in social communication in daily life?" and the response categories are: very interested, interested, just so so, not very interested, and disgusted.

The convenience of media use was measured using the question: "Which medium is the most convenient for you to use?", Response categories include newspapers, magazines, radio, TV, Internet (PC Internet and Mobile Internet), and none. Respondents were categorized into two groups: Those responding that it was easy to use newspapers, magazines, radio, TV, or Internet were placed in the category of having convenient access to media use, and those answering none were categorized as having no convenient media access.

Additional questions asked respondents demographic variables dealing with age, education level, income, gender, and occupation. 
We conducted our survey to Beijing, a city known for its problems with air pollution. The data were obtained through a random digit dialing (RDD) telephone survey in a computer-assisted-telephone-interview (CATI) lab in a large research university in Beijing after two pretests. The orders of choices of each multiple question were randomly arranged to eliminate the biases of selection preferences.

The target population of the survey was Beijing residents at the age of 15 or above. The landline phone numbers were obtained through two processes: The first four digits of numbers were the district numbers, which were geographically proportionately selected through PPS (probability-proportional-to-size sampling) procedure, and the last four digits of the numbers were added by the computer-generated random selection. The final sample size is 697 , which translates into a sampling error of $3.7 \%$ for the entire sample with $95 \%$ confidence level. The final response rate is $14.91 \%$, using the RR3 formula of the American Association of Public Opinion Research (AAPOR) (AAPOR, 2015).

The telephone survey was conducted in January 2015, a time with no major events. To guarantee a relatively high response rate and ensure the respondents were not at work, we conducted the survey from Monday to Friday from 6:00 p.m. to 9:00 p.m. We conducted the survey in three time periods on Saturday and Sunday-9:00 a.m. to noon, 2:00 p.m. to 5:00 p.m., and 6:00 p.m. to 9:00 p.m. All the interviewers of the survey were university students, trained by the researchers.

There is some potential bias in the sampling. More and more Chinese use cellphones while fewer households maintain landline phones, e.g., the Ministry of Industry and Information Technology of China (MIIT) showed there were 18.3 landline phone sets per 100 peoples and 94.5 cell phones per 100 peoples in 2014 in China (MIIT, 2015). But due to technical constraints, we could not contact mobile-only residents. The results show that the percentage of female respondents is $54.81 \%$ and the percentage of respondents between 60-64 is 10.58\%, which are higher than the parameters of Beijing residents of $49.82 \%$ and $5.1 \%$ as of the end of 2014 (Beijing Statistics Bureau, 2015). To compensate for these known biases, the sample data were weighted for analysis based on the joint distribution of the gender, education, and age in the population in Beijing in December 2014. All results reported below are based on the weighted data.

\section{Results}

\section{Sample Description}

Most respondents say their attention on the air pollution issue was extremely affected (9.2\%) or affected $(49.05 \%)$ by media coverage, and only $9.4 \%$ of the respondents claim no impact from media, indicating that there is a relatively strong perception of an agenda-setting effect on the issue. Most respondents assert that media reinforce negative attitudes toward the air pollution, e.g., air pollution is very harmful $(60.23 \%)$, and only $18.27 \%$ of them claim positively that media coverage on air pollution would arouse concern on circumstances and would finally promote the upgrading of lifestyle and sustainable production. The result indicates the media reinforce the negative attribute of air pollution issue.

\section{Impacts on Issue Agenda-Setting}

To test Hypotheses 1a, 2a, 3a, 3c, and 4a (e.g., the impact of media credibility, personal experience, media exposure, convenience of media use, and interpersonal communication on the issue agenda-setting effect), we carried out a multivariate analysis using the four independent variables, five demographic variables (age, gender, income, occupation, and education) as control variables, and the perceived impact by media as dependent variable. Because the dependent variable is an ordinal variable (extremely affected, affected, not 
sure, somewhat affected, and not affected at all, excluding not concerned about the issue of air pollution), we run ordinal logistic regression (OLR) for the analysis, with nested Model 1 only including demographics, Model 2 including demographics and attitudes, and Model 3 with all variables (full model with demographics, attitudes, and behaviors). All of the results are shown in Table 1.

Table 1

Ordinal Logistic Regression Model for Issue (First-Level) Agenda-Setting Effects

\begin{tabular}{|c|c|c|c|}
\hline $\begin{array}{l}\text { Extent influenced by the media coverage } \\
(\text { no impact }=0 \text {, extreme impact }=5)\end{array}$ & Model 1 & Model 2 & Model 3 \\
\hline Age & 0.0039 & 0.0015 & 0.0008 \\
\hline Gender $($ male $=0)$ & -0.027 & -0.0097 & -0.024 \\
\hline \multicolumn{4}{|l|}{ Occupation (blue-collar workers $=0$ ) } \\
\hline White-collar employees & 0.27 & 0.19 & 0.17 \\
\hline Students & -0.34 & -0.57 & -0.59 \\
\hline Professional/managerial & 0.41 & 0.19 & 0.27 \\
\hline The retired & 0.31 & 0.11 & 0.11 \\
\hline Others & 0.49 & 0.46 & 0.46 \\
\hline \multicolumn{4}{|l|}{ Monthly income $(¥ 2000$ and below $=0)$} \\
\hline$¥ 2000-3999$ & -0.13 & -0.20 & -0.11 \\
\hline$¥ 4000-5999$ & -0.04 & -0.12 & -0.11 \\
\hline$¥ 6000-7999$ & -0.30 & -0.57 & -0.47 \\
\hline$¥ 8000-9999$ & 0.30 & 0.14 & -0.02 \\
\hline Yover 10000 & 0.20 & 0.09 & 0.03 \\
\hline \multicolumn{4}{|l|}{ Education (primary school and below $=0$ ) } \\
\hline Middle school or technical secondary & $0.86^{*}$ & 0.74 & 0.64 \\
\hline Junior college & 0.71 & 0.56 & 0.40 \\
\hline Bachelor degree or above & 0.66 & 0.53 & 0.32 \\
\hline Credibility of media (not credible $=0$ ) & & $0.50^{* *}$ & $0.42^{*}$ \\
\hline Direct personal experience with the issue & & $0.27^{* * *}$ & $0.20^{* *}$ \\
\hline Media exposure frequency & & & $0.14^{* *}$ \\
\hline Extent of interpersonal communication & & & $0.19^{*}$ \\
\hline Convenience of media use (not convenient $=0$ ) & & & 0.44 \\
\hline Intercept & -1.20 & -0.36 & 0.48 \\
\hline$F$ & 0.92 & $1.84^{* *}$ & $1.87^{* *}$ \\
\hline
\end{tabular}

Notes. ${ }^{*} p<0.10 ;{ }^{* *} p<0.05 ;{ }^{* * *} p<0.01$.

(1) Test of Hypothesis 1a: impact of credibility. The results show that media credibility significantly impacted the perception of agenda-setting effects in both Model 2 and Model 3. The individuals who believe the media are credible are likely to believe they are influenced by media on the air pollution issue compared with those who do not believe the media are credible. Therefore, H1a is supported.

(2) Test of Hypothesis 2a: impact of personal experience. The five-scale variable of direct personal experience on air pollution issue has a significant impact on perceptions of the agenda-setting effect: The more direct personal experience individuals have with the air pollution issue, the more likely their perceptions on air pollution issue is influenced by media coverage. The impact holds for both Model 2 and Model 3, therefore, $\mathrm{H} 2 \mathrm{a}$ is sufficiently supported. 
(3) Test of Hypothesis 3a/3c: impact of media exposure. As a composite variable on exposure frequency to five media (newspaper, magazine, radio, TV, Internet including Wechat and other mobile Internet) in the last week, media exposure frequency has a significantly positive impact on perceptions of air pollution issue agenda-setting. The more frequently individuals use media, the more likely they would perceive influences by media on the issue. But compared with individuals who cannot access media conveniently, there is no significant difference for those who can access media conveniently. Therefore, H3a is supported, but H3c is not supported.

(4) Test of Hypothesis 4a: impact of interpersonal communication. The interpersonal communication has a slight significant impact on perceptions of an issue agenda-setting effect. The more an individual communicates with others, the more likely he or she would perceive influence by the media on the issue. Though the impact is only significant at 0.10 level, $\mathrm{H} 4 \mathrm{a}$ is generally supported.

The global $F$ test of Model 3 as a whole is 1.87 , significant at 0.05 level, suggesting that the model is significant in explaining perceptions of the agenda-setting effect. Because Model 1 is not statistically significant, Model 2 and Model 3 are more efficient.

\section{Impacts on Attribute Agenda-setting}

The models above test the perceptions of issue agenda-setting effects (e.g., first-level agenda-setting), that is to say, we test whether media can tell the people what to think about and what the agenda-setting researchers originally focused on. To test whether media influence people regarding how to think (second-level agenda-setting), we include the how variable as the dependent variable (negative, positive, uncertain or neutral, and effectless). To test the impact of media on different evaluations on air pollution issue, we run multinomial logistic regression (MLR) to test each of three attributes (negative, positive, and effectless) versus the reference group (uncertain or neutral). The results of MLR (see Table 2) are the same as multiple binary logistic regressions.

(1) Test of Hypothesis 1b: impact of credibility. The media credibility significantly impacts the attribute agenda-setting effects in two of three pairs of comparisons in MLR. The media coverage on air pollution significantly reinforces the individuals to think positively or negatively towards the issue, compared with uncertain (or neutral) attitude. But compared with individuals claiming uncertainty on media's effects on their attitudes towards the air pollution issue, there exists no significant difference for those claiming media have no effect on their attitude toward air pollution issue. Therefore, H1b is only partly supported.

(2) Test of Hypothesis 2b: impact of personal experience. Direct personal experience with the air pollution issue has a significantly diverse impact on three comparisons. That is to say, the more experience individuals have with the air pollution, the more negatively $(p<0.05)$ that media would reinforce their attitudes on the issue. But meanwhile, the more experience with air pollution also leads to more positive attitudes $(p<0.05)$ or no attitudes $(\mathrm{p}<0.10)$ toward it. In light of the hypothesis, we conclude H2b also gets partial support.

(3) Test of Hypothesis $3 \mathrm{~b} / 3 \mathrm{~d}$ : impact of media exposure. Media exposure frequency does not have a significant impact in three comparisons of attitudes toward the media reinforcing the respondents' views on the air pollution issue. That is to say, media exposure frequency has no significant effect on perceptions of media's influence on how to think of air pollution issue, and convenience of media use has no significant impact on attribute agenda-setting either. Therefore, $\mathrm{H} 3 \mathrm{~b}$ and $\mathrm{H} 3 \mathrm{~d}$ are not supported.

Test of Hypothesis $4 \mathrm{~b}$ : impact of interpersonal communication. Three pairs of comparison do not have significant differences on the impact of interpersonal communication. Therefore, similar with H3b, H4b is not support. 
Demographically, students tend to believe that media reinforce their positive, negative, or effectless attitudes toward air pollution issue compared with farmers or blue-collar workers (reference group), indicating students tend to go to extremes towards the air pollution issue. Similarly, compared with individuals with monthly income of $¥ 2000$ and below, those who have higher monthly incomes ( $¥ 4000-5999$ and $¥ 8000-9999$ ) tend to be reinforced significantly positively or negatively by media towards air pollution issue, which indicates that relatively wealthy people hold critical attitudes toward air pollution issue reinforced by media.

Table 2

Multinomial Logistic Regression Model for Attribute (Second-Level) Agenda-setting Effects

\begin{tabular}{|c|c|c|c|}
\hline $\begin{array}{l}\text { Attributes influenced by the media coverage } \\
\text { (positive, negative, effectless, and neutral) }\end{array}$ & $\begin{array}{l}\text { Positive } \\
\text { vs. } \\
\text { neutral }\end{array}$ & $\begin{array}{l}\text { Negative } \\
\text { vs. } \\
\text { neutral }\end{array}$ & $\begin{array}{l}\text { Effectless } \\
\text { vs. } \\
\text { neutral }\end{array}$ \\
\hline Age & 0.02 & 0.02 & 0.03 \\
\hline Gender $($ male $=0)$ & 0.15 & 0.22 & 0.20 \\
\hline \multicolumn{4}{|l|}{ Occupation (blue-collar workers $=0$ ) } \\
\hline White-collar employees & $2.2982^{*}$ & -0.17 & 1.39 \\
\hline Students & $3.7133^{* *}$ & $2.4295^{* *}$ & $2.8657^{* *}$ \\
\hline Professional/managerial & 2.12 & -0.05 & 0.51 \\
\hline The retired & 1.47 & 0.08 & 0.08 \\
\hline Others & $3.5383^{* * *}$ & 1.00 & 1.86 \\
\hline \multicolumn{4}{|l|}{ Monthly income ( $¥ 2000$ and below $=0$ ) } \\
\hline$¥ 2000-3999$ & $1.2063^{*}$ & 0.71 & 0.41 \\
\hline$¥ 4000-5999$ & $1.9031^{* *}$ & $1.4345^{* *}$ & 0.59 \\
\hline$¥ 6000-7999$ & 1.39 & 1.12 & 0.46 \\
\hline$¥ 8000-9999$ & $3.3512^{* * *}$ & $2.3852^{* *}$ & 0.87 \\
\hline Yover 10000 & 1.60 & $1.8804^{*}$ & 0.77 \\
\hline \multicolumn{4}{|l|}{ Education (primary school and below $=0$ ) } \\
\hline Middle school or technical secondary & 0.58 & -0.34 & 0.09 \\
\hline Junior college & 0.71 & -0.08 & -0.24 \\
\hline Bachelor degree or above & -0.38 & -0.78 & -0.16 \\
\hline Credibility of media (not credible $=0$ ) & $0.7271^{*}$ & $0.7430^{* *}$ & 0.08 \\
\hline Direct personal experience with the issue & $0.4770^{* *}$ & $0.3228^{* *}$ & $0.3654^{*}$ \\
\hline Media exposure & 0.02 & 0.05 & -0.08 \\
\hline Extent of interpersonal communication & 0.01 & 0.03 & -0.06 \\
\hline Convenience of media use (not convenient $=0$ ) & -0.70 & -0.13 & -0.95 \\
\hline Intercept & $-3.5290^{*}$ & 0.33 & -1.90 \\
\hline$F$ & $-3.53^{*}$ & & \\
\hline
\end{tabular}

Notes. ${ }^{*} p<0.10 ;{ }^{* *} p<0.05 ;{ }^{* * *} p<0.01$.

\section{Conclusion and Discussion}

The current study examined self-awareness of both issue agenda-setting and attribute agenda-setting through a self-reported survey. The results generally support a model that individuals perceive strong media agenda-setting effects for the issue of air pollution based on their perceptions of the credibility of the news media, personal experience with the issue, interpersonal communication, and exposure to the media. The model is partially supported for perceived media attribute agenda-setting. 
As predicted, individuals thinking that the media are credible tend to believe they are highly influenced by media on the perceived importance of the air pollution issue, compared with those who do not believe that the media are credible. In other words, respondents tend to believe that credible media influence them. Direct personal experience on the issue also increases the perception of the issue agenda-setting effect. On the one hand, the more experience individuals have with a certain issue, the more likely they would seek information from channels including media, and therefore they are more likely to perceive influence by the media coverage. On the other hand, the interaction between direct personal experience and media coverage on a certain issue would increase one's attention on that issue. Therefore, direct personal experience is like a catalyst and bridge of agenda setting. There could not exist a strong perception on agenda-setting effect for the issue without interest and personal experience. For example, the media coverage of international politics has little impact on those who are not interested in them (Wanta \& HU, 1993). Connected with personal experience, media exposure has a positive impact on perceptions of issue agenda-setting. The more individuals expose themselves to media, the more likely they are interested in the issue and more likely they perceive influence by media coverage.

Finally, interpersonal communication has a positive impact on perceptions of the agenda-setting effect for the air pollution issue. The more individuals take part in interpersonal communication, the more likely they would exchange information (including that from the media) and the more information they would get from others about media reports on certain issues. For example, Under the Domeis, a widely diffused online documentary criticizing air pollution in China in March 2015, was intensively discussed on social media (Tran, 2015). Interpersonal communication and media exposure both play important roles in agenda-setting process, but it is unclear which comes first (Wanta, 1997, p. 47). Perhaps they interact with each other and jointly influence perceptions of agenda-setting effects.

The impact on attribute agenda-setting shows different patterns from the issue agenda-setting. Similarly with the issue agenda-setting, attitudinal variables - media credibility and direct personal experience - have significant impacts in two or three comparisons in the model. But behavioral variables-media exposure and interpersonal communication - have no impact on self-awareness of attribute agenda-setting. While first-level agenda-setting effects can widely result from the sheer volume of exposure to news content, research at the second level/attribute agenda-setting effects suggests that "closer attention to the specific content of media messages provides a more detailed understanding of the pictures in our heads and the attitudes and opinions grounded in those the pictures" (McCombs, 2013, p. 120).

Interestingly, the impacts of media credibility and direct personal experience are in opposite directions: The individuals trusting the media would think about the air pollution issue more positively or more negatively, compared with those who do not trust the media or without much personal experience. The results confirm that different credible media outlets (e.g., party media vs. market-oriented media) perceived by individuals might emphasize different attributes of the issue. The direct personal experience does not only result in positive attitudes toward air pollution issue. Instead, it enhances the polarization of attitudes (positive, negative, or effectless) compared with neutral attitudes. The more direct personal experience an individual has, the more independently he/she thinks about the issue. Borrowing from Lazarsfeld's concept of political predisposition and cognitive dissonance theory of Leon Festinger, to reach cognitive consonance, the media's influences on attributes only strengthen the existing attitudes of the individuals through their selective exposure, selective perception, and selective retention. 
Though media exposure and interpersonal communication have significant impacts on perceptions of the issue agenda-setting effect, these behavior variables have no impact on how individuals think about the air pollution issue. This may be largely due to the fact that attribute agenda-setting mainly deals with attitudes, but both media exposure and interpersonal communication instead deal with behavior. Individuals in collectivist cultures in China are usually thought to possess a low-level interpersonal influence, which would decrease their interpersonal influences on each other's agenda.

Moreover, in cases where disagreement might be felt among individuals, the collectivism culture prevents free expression, where there is often a spiral of silence when their personal agenda deviates from the social norms. The absence of the impact of media use further indicates that Chinese media mainly reinforce, instead of changing the audiences' existing attitudes. That is to say, Chinese media are effective in telling people what to think about, but not effective in telling them how to think, consistent with what Cohen originally noted, that the press "may not be successful much of the time in telling people what to think, but it is stunningly successful in telling its readers what to think about" (McCombs \& Shaw, 1972, pp. 176-187). There may be two explanations for this:

Firstly, the media in China are not effective in telling the audience how to think, but are very effective at story-telling, largely because of the lack of their credibility. The audience does not believe the guidance of media, but only the facts; Secondly, media in China try to put their emphasis on news reporting instead of comments (editorials), because that is a relatively safe way. For example, the documentary Under the Domeis, mentioned earlier, was soon forbidden in 2015 in China (Gardner, 2015). The area needs further exploration in the future. Compared with the OLR model, the MLR model shows that the perceptions of attribute agenda-setting is more demographically influenced than the perceptions of issue agenda-setting. The MLR model shows that students and those with relatively more monthly income tend to hold more diversified opinions on the air pollution issue. But demographics show almost no impact on the salience transferal function of media, which may be common in China. This indicates that the issue agenda-setting effect is ubiquitous and does not change among people with different demographic traits, but the attribute agenda-setting effect depends much on the demographical traits.

There are some limitations in the current study. The single question to operationalize the dependent variable (perceptions of the agenda-setting effect) may be too simple. The issue of air pollution may not be representative. To ensure the validity and reliability of the measurement of perceived agenda-setting, multiple-item scales for multiple issues may be more appropriate, both for perception of issue agenda-setting and attribute agenda-setting effects. More sophisticated operationalization of some other variables would be also necessary. In the measurement of credibility and convenience, we only employed single dichotomous variables for parsimony. In the future research, mulita-item scales should be introduced to measure the variables such as credibility, convenience, and interpersonal communication more reliably. Methodologically, the survey was conducted through landline calls, which could be somehow biased as discussed in the methods section. There are more and more cell phone-only telephone subscribers in China recently, with the rapid diffusion of mobile phones. Nonetheless, despite these shortcomings, the current study demonstrates the fruitfulness of examining respondents' perceptions of the agenda-setting effect. Respondents clearly identified the effect that some researchers previously argued was "inadvertent" (McCombs, 1997). While our findings also clear up some factors influencing this effect, future research should continue to examine the media's impact on the world's largest population to add additional clarity to this important societal influence. 


\section{References}

AAPOR. (2015). Standard definitions final dispositions of case codes and outcome rates for surveys. Retrieved from http://www.aapor.org/Standards-Ethics/Standard-Definitions-(1).aspx

Atwater, T., Salwen, M. B., \& Anderson, R. B. (1985). Interpersonal discussion as a potential barrier to agenda-setting. Newspaper Research Journal, 6(4), 37-43.

Atwood, E. (1980). From press releases to voting reasons: Tracing the agenda in a congressional campaign. Communication yearbook, 4, 467-482.

Beijing Statistics Bureau. (2015). Beijing statistics yearbook 2015. Beijing: China Statistics Press.

CNNIC. (2016). The statistical report of Internet development of China. Retrieved from http://cnnic.cn/gywm/xwzx/rdxw/2015/201601/t20160122_53283.htm

Coleman, R., \& McCombs, M. (2007). The young and agenda-less? Exploring age-related differences in agenda setting on the youngest generation, baby boomers, and the civic generation. Journalism \& Mass Communication Quarterly, 84(3), 495-508.

Dearing, J. W., \& Rogers, E. (1996). Agenda-setting (Vol. 6). Thousand Oaks, CA: Sage publications.

Demers, D. P., Craff, D., Choi, Y. H., \& Pessin, B. M. (1989). Issue obtrusiveness and the agenda-setting effects of national network news. Communication Research, 16(6), 793-812.

Duan, R., \& Takahashi, B. (2016). The two-way flow of news: A comparative study of American and Chinese newspaper coverage of Beijing's air pollution. International Communication Gazette, 25.

Festinger, L. (1962). A theory of cognitive dissonance (Vol. 2). Stanford, California: Stanford University Press.

Gardner, D. K. (2015). China's "Silent Spring” moment? Why "Under the Dome" found a ready audience in China. Retrieved from http:/www.nytimes.com/2015/03/19/opinion/why-under-the-dome-found-a-ready-audience-in-china.html?_r=0

Gross, K., \& Aday, S. (2003). The scary world in your living room and neighborhood: Using local broadcast news, neighborhood crime rates, and personal experience to test agenda setting and cultivation. Journal of Communication, 53(3), 411-426.

HE, Z. (2009). Political communication in dual discourse universes. In L. Willant, \& A. Aw (Eds.), Political communication in Asia (pp. 43-71). New York, NY: Routledge.

Hill, D. B. (1985). Viewer characteristics and agenda setting by television news. Public Opinion Quarterly, 49(3), 340-350.

Iyengar, S., \& Kinder, D. R. (2010). News that matters: Television and American opinion. Chicago: University of Chicago Press.

Johnson, T. J., \& Kaye, B. K. (2000). Using is believing: The influence of reliance on the credibility of online political information among politically interested Internet users. Journalism \& mass communication quarterly, 77(4), 865-879.

King, G., PAN, J., \& Roberts, M. E. (2013). How censorship in China allows government criticism but silences collective expression. American Political Science Review, 107(2), 326-343.

Lasorsa, D. L., \& Wanta, W. (1990). Effects of personal, interpersonal and media experiences on issue saliences. Journalism \& Mass Communication Quarterly, 67(4), 804-813.

Lee, J. K. (2015). Knowledge as a measure of news reception in the agenda-setting process. Journal of Broadcasting \& Electronic Media, 59(1), 22-40.

Levin, D. (2015). Study links polluted air in China to 1.6 million deaths a year. Retrieved from http://www.nytimes.com/2015/08/14/world/asia/study-links-polluted-air-in-china-to-1-6-million-deaths-a-year.html?_r=0

LUO, Y. (2013). Mapping agenda-setting research in China: A meta-analysis study. Chinese Journal of Communication, 6(3), 269-285.

McCombs, M. (1997). Building consensus: The news media's agenda-setting roles. Political Communication, 14(4), 433-443.

McCombs, M. (2013). Setting the agenda: The mass media and public opinion. Hoboken, NJ: John Wiley \& Sons.

McCombs, M. E., \& Shaw, D. L. (1972). The agenda-setting function of mass media. Public opinion quarterly, 36(2), $176-187$.

McLeod, J. M., Becker, L. B., \& Byrnes, J. E. (1974). Another look at the agenda-setting function of the press. Communication Research, 1(2), 131-166.

Mendelsohn, M. (1996). The media and interpersonal communications: The priming of issues, leaders, and party identification. The Journal of Politics, 58(1), 112-125.

MIIT. (2015). The annual report on telecommunications in China (2014). Retrieved from http://www.miit.gov.cn/n1146312/n1146904/n1648372/c3337169/content.html

Miller, R. E., \& Wanta, W. (1996). Sources of the public agenda: The president-press-public relationship. International Journal of Public Opinion Research, 8(4), 390-402. 
Mullins, L. E. (1977). Agenda-setting and the young voter. In D. L. Shaw, \& M. E. McCombs (Eds.), The emergence of American political issues: The agenda setting function of the press. New York: West.

Shaw, D. L., McCombs, M., Weaver, D. H., \& Hamm, B. J. (1999). Individuals, groups, and agenda melding: A theory of social dissonance. International Journal of Public Opinion Research, 11(1), 2-24.

Shaw, E. F. (1977). The agenda-setting hypothesis reconsidered: Interpersonal factors. International Communication Gazette, 23(4), 230-240.

Tran, M. (2015). Phenomenal success for new film that criticizes China's environmental policy. Retrieved from http://www.theguardian.com/world/2015/mar/02/china-environmental-policy-documentary-under-the-dome-chai-jing-video

Vu, H. N. N., \& Gehrau, V. (2010). Agenda diffusion: An integrated model of agenda setting and interpersonal communication. Journalism \& Mass Communication Quarterly, 87(1), 100-116.

Wanta, W. (1997). The public and the national agenda: How people learn about important issues. Mahwah, NJ: Lawrence Erlbaum Associates.

Wanta, W., \& HU, Y. W. (1993). The agenda-setting effects of international news coverage: An examination of differing news frames. International Journal of Public Opinion Research, 5(3), 250-264.

Wanta, W., \& HU, Y. W. (1994). The effects of credibility, reliance, and exposure on media agenda-setting: A path analysis model. Journalism \& Mass Communication Quarterly, 71(1), 90-98.

Wanta, W., \& WU, Y. C. (1992). Interpersonal communication and the agenda-setting process. Journalism \& Mass Communication Quarterly, 69(4), 847-855.

Weaver, D. H. (1981). Media agenda-setting in a presidential election: Issues, images, and interest. New York: Praeger Publishers.

Weaver, D. H., ZHU, J. H., \& Willnat, L. (1992). The bridging function of interpersonal communication in agenda-setting. Journalism \& Mass Communication Quarterly, 69(4), 856-867.

ZHANG, G., SHAO, G., \& Bowman, N. D. (2012). What is most important for my country is not most important for me agenda-setting effects in China. Communication Research, 39(5), 662-678.

ZHU, J. (1997). Antecedents, covariates, and outcomes of media credibility in China. Mass Communication Review, 24(3/4), 4-17.

ZHU, J. H., Watt, J. H., Snyder, L. B., YAN, J., \& JIANG, Y. (1993). Public issue priority formation: Media agenda-setting and social interaction. Journal of Communication, 43(1), 8-29.

Zucker, H. G. (1978). The variable nature of news media influence. Communication Yearbook, 2, 225-240. 